The findings of Repo et al. follow logically on from our current understanding of nitrous oxide formation. It is well known that $\mathrm{N}_{2} \mathrm{O}$-producing bacteria are adapted to cold soil environments ${ }^{2}$, and that $\mathrm{N}_{2} \mathrm{O}$ emissions are location specific $\mathrm{c}^{4}$ and episodic in time ${ }^{3}$. Furthermore, experimental manipulations have indicated that tundra may be capable of emitting $\mathrm{N}_{2} \mathrm{O}$ (ref. 5), although at a scale far below that reported in this study. Thus, one might have expected restricted enclaves of Arctic tundra, where frost action has resulted in the accumulation of moisture and nutrients, to foster high levels of $\mathrm{N}_{2} \mathrm{O}$ production, and this is what Repo et al. have shown.
Of course, the study by Repo et al. ${ }^{1}$ is both spatially and temporally limited. Given the episodic nature of $\mathrm{N}_{2} \mathrm{O}$ emissions in both space and time $e^{3,4}$, one would usually expect a higher time resolution in modern datasets reporting seasonal $\mathrm{N}_{2} \mathrm{O}$ fluxes. Thus, extrapolations made using the current dataset are highly uncertain and will need to be backed up with measurements of a higher temporal and spatial resolution (Fig. 1). Nevertheless, the observation of high nitrous oxide emissions from Arctic peat circles opens up a new dimension of interactions between climate and tundra, and may well expand the focus of nitrous oxide research - which until now has focused on nutrient-rich temperate and tropical soils - to include the terrestrial Arctic environment.

Torben R. Christensen is at the GeoBiosphere Science Centre, Lund University, Sölvegatan 12, 22362 Lund, Sweden.

e-mail: torben.christensen@nateko.lu.se

References

1. Repo, M. E. et al. Nature Geosci. 2, 189-192 (2009).

2. Christensen, S. \& Christensen, B. T. J. Soil Sci. 42, 637-647 (1991)

3. Papen, H. \& Butterbach-Bahl, K. J. Geophys. Res. 114, 18487-18503 (1999).

4. Parkin, T. B. Soil Sci. Soc. Am. I. 51, 1194-1199 (1987).

5. Christensen, T. R., Michelsen, A. \& Jonasson, S. Soil Biol. Biochem. 31, 637-641 (1999).

\title{
CARBON CAPTURE
}

\section{Made to measure}

The world's tropical forests are disappearing fast. Intensive logging, the rise in subsistence farming and now the biofuel boom are all taking their toll on the tropics. Indeed, reports warn that Indonesia could be stripped of its rainforests in the next few decades, and that Columbian forests will soon be converted into cocaine. This global-scale destruction is wiping out species, destroying the livelihoods of indigenous people, instigating conflict and jeopardising the stability of the global climate system.

Tropical forests are huge carbon processors, soaking up and releasing around six times the amount of carbon dioxide generated by fossil-fuel burning each year. A small shift in the ability of these ecosystems to cycle carbon dioxide could have severe knock-on effects for climate. However, we know little about how carbon flux into and out of these vast ecosystems has changed over the past century - mainly due to the difficulty in maintaining observational networks in these inaccessible regions.

Indirect estimates of tropical carbon flux - obtained by adding up known carbon sinks and sources, and attributing any imbalance to tropical forests - indicate that globally these ecosystems are a net carbon sink. Unfortunately, aside from being a very rough and ready approach, this tells us nothing about the location of these sinks. Although ground-based measurements in South America indicate that the Amazonian rainforest may contribute

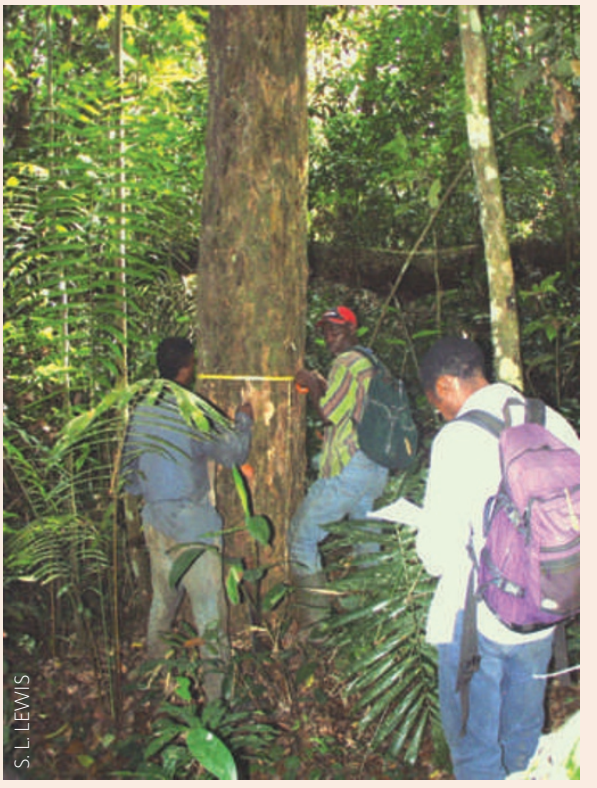

AFRITRON (African Tropical Rainforest Observation Network). Using an equation that relates tree girth to total biomass, they were able to calculate how much carbon was stored in the trees when the measurements were made. Furthermore, by examining how tree diameter changed between 1968 and 2007, they could work out how much carbon the trees had accumulated over this period. When data from all the plots were taken together tree diameter was found to increase significantly, suggesting that carbon storage increased substantially in the second half of the twentieth century.

Extrapolated to the whole of the African continent, the data indicate that African tropical forests may have sequestered $0.34 \mathrm{Pg}$ of carbon per year over this forty-year period, which is comparable to the amount of carbon released by deforestation in tropical Africa. Of course, as the authors note, a limited number of sampling locations, together with a complete lack of measurements in some areas (such as central Democratic Republic of Congo) means that these numbers are only an educated first guess.

Even so, in a world that is beginning to notice the effects of past increases in atmospheric carbon dioxide concentrations, and without a reversal of this trend in sight, living tropical trees may soon look more precious than soy beans for fuel, teak for furniture and cocaine for western high society put together.

ANNA ARMSTRONG 